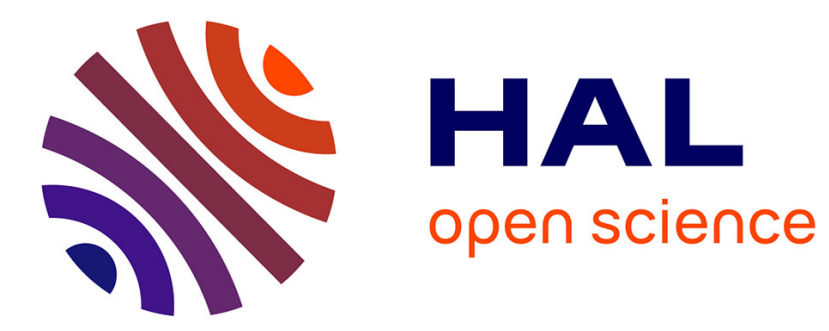

\title{
The quantum Hall effect in modulation doped In0.53Ga 0.47As-InP heterojunctions
}

\author{
Y. Guldner, J.P. Hirtz, J.P. Vieren, P. Voisin, M. Voos, M. Razeghi
}

\section{To cite this version:}

Y. Guldner, J.P. Hirtz, J.P. Vieren, P. Voisin, M. Voos, et al.. The quantum Hall effect in modulation doped In0.53Ga 0.47As-InP heterojunctions. Journal de Physique Lettres, 1982, 43 (16), pp.613-616. 10.1051/jphyslet:019820043016061300 . jpa-00232099

\section{HAL Id: jpa-00232099 https://hal.science/jpa-00232099}

Submitted on 1 Jan 1982

HAL is a multi-disciplinary open access archive for the deposit and dissemination of scientific research documents, whether they are published or not. The documents may come from teaching and research institutions in France or abroad, or from public or private research centers.
L'archive ouverte pluridisciplinaire HAL, est destinée au dépôt et à la diffusion de documents scientifiques de niveau recherche, publiés ou non, émanant des établissements d'enseignement et de recherche français ou étrangers, des laboratoires publics ou privés. 
Classification

Physics Abstracts

72.90

\title{
The quantum Hall effect in modulation doped $\mathrm{In}_{\mathbf{0 . 5 3}} \mathbf{G a}_{\mathbf{0 . 4 7}} \mathbf{A s - I n P}$ heterojunctions
}

\author{
Y. Guldner $\left({ }^{*}\right)$, J. P. Hirtz $\left({ }^{* *}\right)$, J. P. Vieren $\left({ }^{*}\right)$, \\ P. Voisin (*), M. Voos (*) and M. Razeghi $\left({ }^{* *}\right)$ \\ $\left({ }^{*}\right)$ Groupe de Physique des Solides $\left({ }^{+}\right)$de l'Ecole Normale Supérieure, 24, rue Lhomond, 75005 Paris, \\ France \\ ${ }^{(* *)}$ Laboratoire Central de Recherche, Thomson-C.S.F., 91401 Orsay, France
}

(Reçu le 26 mai 1982, révisé le 21 juin, accepté le 29 juin 1982)

\begin{abstract}
Résumé. - Nous décrivons la première observation à 4,2 et 1,5 $\mathrm{K}$ de l'effet Hall quantique dans les hétérojonctions $\mathrm{In}_{0,53} \mathrm{Ga}_{0,47} \mathrm{As}$-InP à dopage modulé. Ces résultats sont ensuite comparés à ceux obtenus sur une hétérojonction $\mathrm{GaAs}-\mathrm{Al}_{x} \mathrm{Ga}_{1-x} \mathrm{As}$ ayant des caractéristiques électroniques semblables.
\end{abstract}

\begin{abstract}
We report the first observation of the quantum Hall effect in modulation doped $\mathrm{In}_{0.53} \mathrm{Ga}_{0.47} \mathrm{As}$-InP heterojunctions at 4.2 and $1.5 \mathrm{~K}$. The results are then compared to data obtained in a $\mathrm{GaAs}-\mathrm{Al}_{x} \mathrm{Ga}_{1-x} \mathrm{As}$ heterojunction having similar electronic characteristics.
\end{abstract}

The quantum Hall effect (QHE), which has recently provided [1,2] a very accurate determination of the fine structure constant, has been observed up to now in Si metal-oxide-semiconductor field-effect transistor [1] and in modulation-doped $\mathrm{GaAs}_{\mathrm{A}} \mathrm{Al}_{x} \mathrm{Ga}_{1-x}$ As heterojunctions [3]. In such systems, a two-dimensional electron gas (2 DEG) is formed at the $\mathrm{Si}_{-} \mathrm{SiO}_{2}$ or GaAs-Al ${ }_{x} \mathrm{Ga}_{1-x}$ As interface, and the QHE manifests in the occurrence of plateaus in the Hall resistance $\left(\rho_{x y}\right)$ of this $2 \mathrm{DEG}$ when the magnetic field $B$, perpendicular to the interface, is swept or when the electron density, $n$, is varied under constant magnetic field. These plateaus correspond to quantized values of $\rho_{x y}$, namely $\rho_{x y}=h / i e^{2}$, where $i=1,2 \ldots$ is the number of filled Landau levels of the $2 \mathrm{DEG}$, and, simultaneously, the magnetoresistance, $\rho_{x x}$, vanishes.

Under magnetic field, the 2 DEG energy is quantized into Landau levels broadened by scattering, each level having a degeneracy $d=e B / h$. When $i$ Landau levels are filled, the gap between empty and filled Landau levels prevents scattering to occur and the density of states at the Fermi level, $E_{\mathrm{F}}$, tends to vanish, so that the diagonal conductivity $\sigma_{x x}$, as well as $\rho_{x x}$, is equal to zero at $T=0$. In this case, the off-diagonal conductivity is $\sigma_{x y}=n e / B$ with $n=i d$, so that $\sigma_{x y}=i e^{2} / h$, leading to $\rho_{x y}=h / i e^{2}$. The observation of plateaus implies that $E_{\mathrm{F}}$ is pinned between Landau levels over finite ranges of $B$ or $n$, instead of jumping from one Landau level to the following one when $B$ or $n$ is swept. Several theoretical models have been proposed to account for the QHE,

( $\left.{ }^{+}\right)$Laboratoire associé au C.N.R.S. 
$E_{\mathrm{F}}$ being pinned either by shallow impurities [4], or by localized states [5-9] in the tails of the broadened Landau levels, as a result of potential fluctuations.

We report here the first observation of the QHE in another system, namely in modulationdoped $\mathrm{In}_{0.53} \mathrm{Ga}_{0.47}$ As-InP heterojunctions. More than ten pronounced plateaus in $\rho_{x y}$ are detected, yielding thus at least as good data as in $\mathrm{GaAs}_{-} \mathrm{Al}_{x} \mathrm{Ga}_{1-x} \mathrm{As}$ structures [3]. The temperadure dependence of the QHE is studied, and the electron $g$ factor is found to be enhanced from the observation of an additional splitting in $\rho_{x x}$ at high magnetic fields. Finally, we compare our results to those obtained in a modulation-doped $\mathrm{GaAs}-\mathrm{Al}_{x} \mathrm{Ga}_{1-x} \mathrm{As}$ heterojunction having comparable electronic characteristics.

The $\mathrm{In}_{0.53} \mathrm{Ga}_{0.47} \mathrm{As}$-InP heterojunctions used here were grown by low-pressure metalorganic chemical vapour deposition [10] on (100) semi-insulating Fe-doped InP substrates. A typical structure is shown schematically in figure $1 a$. The InP and $\operatorname{In}_{0.53} \mathrm{Ga}_{0.47} \mathrm{As}$ epilayers were n-type with $N_{\mathrm{D}}-N_{\mathrm{A}} \sim 3 \times 10^{16}$ and $2 \times 10^{15} \mathrm{~cm}^{-3}$, respectively. Standard Hall bridges (Fig. $1 b$ ) were used to measure $\rho_{x x}$ and $\rho_{x y}$. The magnetic field, perpendicular to the interface, was provided by a superconducting coil, and could be swept continuously from 0 to $10 \mathrm{~T}$. Low field Hall effect measurements gave electron mobilities equal to 9000,37000 and $50000 \mathrm{~cm}^{2} \mathrm{~V}^{-1} \mathrm{~s}^{-1}$ at 300 , 77 and $4.2 \mathrm{~K}$, respectively.

Previous Shubnikov-de Haas and cyclotron resonance measurements have shown [11] that a $2 \mathrm{DEG}$ is actually formed at the interface between InP and $\mathrm{In}_{0.53} \mathrm{Ga}_{0.47}$ As. As in modulation doped GaAs- $\mathrm{Al}_{x} \mathrm{Ga}_{1-x}$ As heterojunctions [12], electrons from the donors in the wide band gap material (InP) are transferred in the narrow gap one $\left(\mathrm{In}_{0.53} \mathrm{Ga}_{0.47} \mathrm{As}\right)$, so that $E_{\mathrm{F}}$ is constant throughout the structure. This results in a 2 DEG confined in the potential well due to the band bending near the interface which is caused by the spatial separation of positive (ionized donors) and negative (electrons) charges, as shown in figure $1 c$.

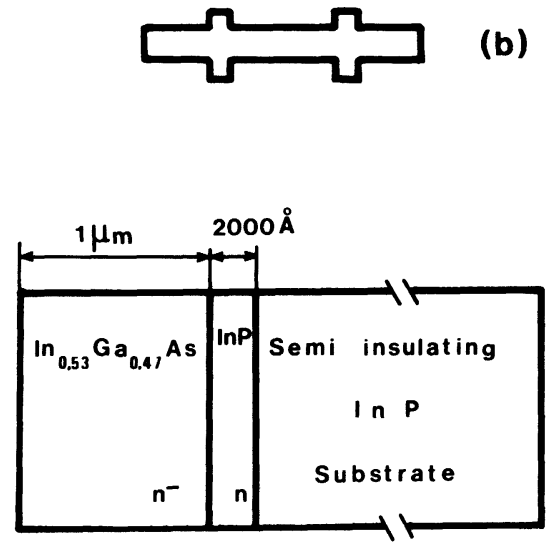

(a)

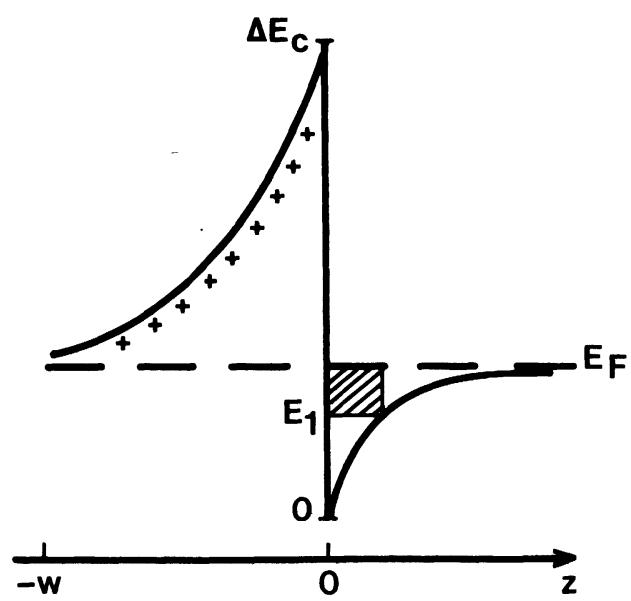

(c)

Fig. 1. - a) Configuration of the modulation doped $\operatorname{In}_{0.53} \mathrm{Ga}_{0.47}$ As-InP heterojunctions used here. b) Geometry of the Hall bridge used here; $\rho_{x x}$ is measured along the length of the sample, and $\rho_{x y}$ perpendicular to it. $c$ ) Schematic energy band diagram corresponding to modulation-doped heterojunctions. The interface is at $z=0, \mathrm{In}_{0.53} \mathrm{Ga}_{0.47}$ As and InP being situated, respectively, on the right and left hand side of the interface. $E_{1}$ and $E_{\mathrm{F}}$ are the ground electron subband and Fermi level, respectively. $\Delta E_{\mathrm{c}}$ is the conduction band discontinuity, at $z=0$, and $W$ is the width of the depletion layer in InP corresponding to the region where donors are ionized (crosses). The hatched area represents the two-dimensional electron gas. 


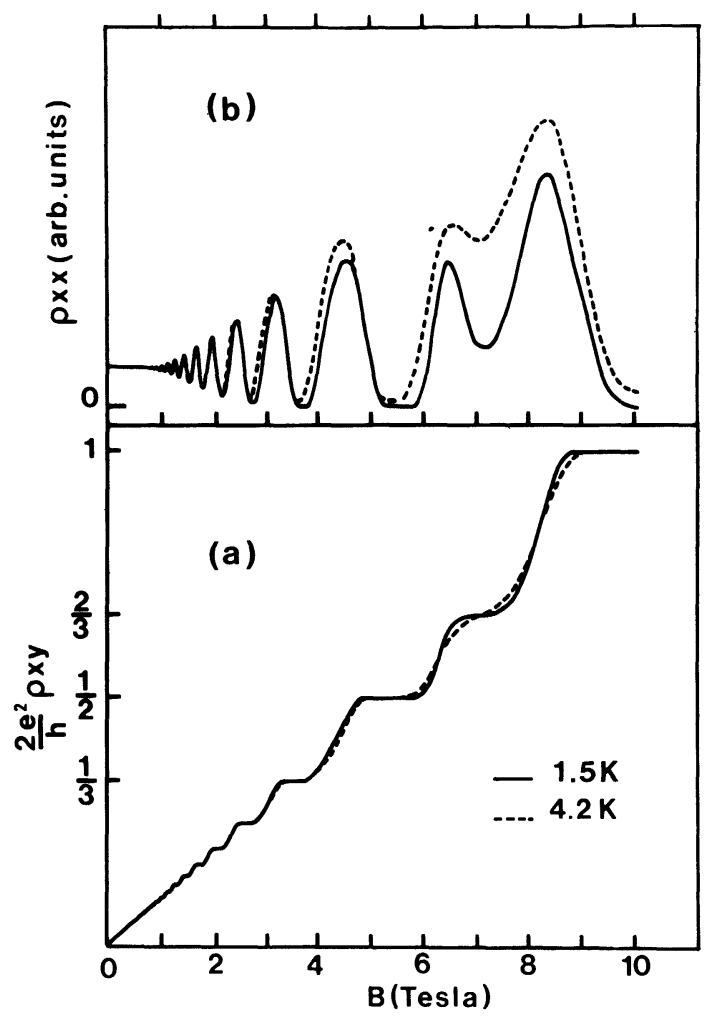

Fig. 2. $-a$ ) Typical results obtained in an $\mathrm{In}_{0.53} \mathrm{Ga}_{0.47}$ As-InP heterojunction. $\rho_{x y}$ as a function of $B$ at 4.2 (dashed line) and $1.5 \mathrm{~K}$ (solid line), with $h / 2 e^{2}=12906 \Omega$. b) $\rho_{x x}$ as a function of $B$ at 4.2 (dashed line) and $1.5 \mathrm{~K}$ (solid line).

Figure 2 gives $\rho_{x x}$ and $\rho_{x y}$ at $4.2 \mathrm{~K}$ and $1.5 \mathrm{~K}$. These results are quite typical of the QHE [1, 2], since they show unambiguously the vanishing of $\rho_{x x}$ and plateaus in $\rho_{x y}$. The oscillations in $\rho_{x x}$ are periodic in $1 / B$, as in usual Shubnikov-de Haas measurements, and the electron density at the interfaces deduced from the period is here $n=5.3 \times 10^{11} \mathrm{~cm}^{-2}$. One can see distinctly in figure $2 a$ at least ten plateaus in $\rho_{x y}$ corresponding to quantized values of the Hall resistance, such as $h / 2 e^{2}, h / 3 e^{2} \ldots$ The first two steps in $\rho_{x y}$ occurring around $8 \mathrm{~T}$ correspond to the spin-splitted $N=1$ Landau levels, and the plateau $h / 3 e^{2}$ to the gap between these two spin-split levels. The magnetic field separation between the midpoints of the two neighbouring steps of this plateau yields an effective electron $g$ factor of the order of 10 at $1.5 \mathrm{~K}$. The $g$ factor is thus enhanced with respect to its bare value which is $\sim 3$ in $\mathrm{In}_{0.53} \mathrm{Ga}_{0.47}$ As [13]. This is certainly due, as in Si MOS structures [14] and $\mathrm{GaAs}-\mathrm{Al}_{x} \mathrm{Ga}_{1-x}$ As heterojunctions [15], to exchange interactions in the $2 \mathrm{DEG}$ [16]. Note that we cannot distinguish plateaus corresponding to $h / 5 e^{2}, h / 7 e^{2} \ldots$ because, for the corresponding values of the magnetic field, the spin splitting of the associated Landau levels is too small and cannot be resolved.

We have also done the same experiments in a modulation-doped $\mathrm{GaAs}-\mathrm{Al}_{0.25} \mathrm{Ga}_{0.75} \mathrm{As}$ heterojunction grown by molecular beam expitaxy, in which the electron density $(n=4 \times$ $\left.10^{11} \mathrm{~cm}^{-2}\right)$ and mobility $(\mu=50000$ at $4.2 \mathrm{~K})$ were comparable to their values in the $\mathrm{In}_{0.53} \mathrm{Ga}_{0.47} \mathrm{As}$-InP heterojunctions studied here. We have obtained data quite similar to those shown in figure 2 , the most striking feature being that, for each quantized value of $\rho_{x y}$ which could be observed in our GaAs- $\mathrm{Al}_{0.25} \mathrm{Ga}_{0.75} \mathrm{As}$ and $\mathrm{In}_{0.53} \mathrm{Ga}_{0.47} \mathrm{As}$-InP heterojunctions, the 
range $\Delta B$ of magnetic field over which the corresponding plateaus extend (i.e. the width of the plateaus) were the same in both structures. This is indeed somewhat surprising because, except for $n$ and $\mu$, the two systems under study here, which were not grown by the same epitaxial method, are actually different. We believe, in fact, that the biggest difference is that the 2 DEG is either confined in $\mathrm{In}_{0.53} \mathrm{Ga}_{0.47} \mathrm{As}$ or in GaAs. Thus, one might expect to have potential fluctuations due to alloy disorder in $\operatorname{In}_{0.53} \mathrm{Ga}_{0.47} \mathrm{As}$-InP heterojunctions which would help in localizing carriers leading [5], for example, to wider plateaus than in $\mathrm{GaAs}-\mathrm{Al}_{x} \mathrm{Ga}_{1-x} \mathrm{As}$ heterojunctions. However, carrier localization is a difficult and subtle problem, and it is not possible to assert definitely from these simple observations, which we cannot explain at the present time, that localization is not involved in the QHE.

To conclude, we think that more experimental and theoretical investigations are clearly required to have a complete understanding of the quantum Hall effect, which is certainly a very interesting and stimulating aspect of semiconductor physics.

Acknowledgments. - We are grateful to J. P. Duchemin and M. A. Poisson for their constant interest in this work. We thank P. Delescluze and Nuyen T. Linh for providing us with the GaAs$\mathrm{Al}_{x} \mathrm{Ga}_{1-x}$ As heterojunction which was grown at Thomson-C.S.F. We are also grateful to G. Toulouse and B. Souillard for fruitful discussions. Finally, the work at Thomson-C.S.F. was supported by the D.G.R.S.T. and D.R.E.T.

\section{References}

[1] Von Klitzing, K., Dorda, G. and Pepper, M., Phys. Rev. Lett. 45 (1980) 494.

[2] Tsui, D. C., Gossard, A. C., Field, B. F., Cage, M. E. and Dziuba, R. F., Phys. Rev. Lett. 48 (1982) 3.

[3] Tsui, D. C. and Gossard, A. C., Appl. Phys. Lett. 38 (1981) 550.

[4] Baraff, G. A. and Tsui, D. C., Phys. Rev. B 24 (1981) 2274.

[5] Aoki, H. and ANdo, T., Solid State Commun. 38 (1981) 1079.

[6] Prange, R. E., Phys. Rev. B 23 (1981) 4802.

[7] Laughlin, R. B., Phys. Rev. B 23 (1981) 5632.

[8] Halperin, B. I., Phys. Rev. B 25 (1982) 2185.

[9] Tsui, D. C. and Allen, S. J., Phys. Rev. B 24 (1981) 4082.

[10] Razeghi, M., Hirtz, P., Larivain, J. P., Blondeau, R., de Cremoux, B. and Dúchemin, J. P., Electron. Lett. 17 (1981) 643.

[11] Guldner, Y., Vieren, J. P., Voisin, P., Voos, M., Razeghi, M. and Poisson, M. A., Appl. Phys. Lett. 40 (1982) 877.

[12] Störmer, H. L., Dingle, R., Gossard, A. C., Wiegmann, W. and Sturge, M. D., Solid State Commun. 29 (1979) 705.

[13] Perea, E. H., Mendez, E. E. and Forstad, C. G., Appl. Phys. Lett. 36 (1980) 978.

[14] Fang, F. F. and Stiles, P. J., Phys. Rev. 174 (1968) 823.

[15] Englert, Th., Tsui, D. C., Gossard, A. C. and Uihlein, Ch., Surf. Sci. 113 (1982) 295.

[16] Ando, T. and Uemura, Y., J. Phys. Soc. Japan 37 (1974) 1044. 